\title{
Nitrogen deposition as an important nutrient from the environment and its impact on ecosystems in China
}

\author{
XueJun $\mathrm{LIU}^{1,2^{*}}$, Ling SONG ${ }^{1}$, ChunE HE ${ }^{1,3}$, FuSuo ZHANG ${ }^{1}$ \\ ${ }^{1}$ College of Resources and Environmental Sciences, China Agricultural University, Beijing 100193, China; \\ ${ }^{2}$ Xinjiang Institute of Ecology and Geography, Chinese Academy of Sciences, Urumqi 830011, China; \\ ${ }^{3}$ Institute of Medicinal Plant Development, Chinese Academy of Medical Sciences and Peking Union Medical College, Beijing \\ 100193, China
}

\begin{abstract}
As an example of atmospheric nitrogen $(\mathrm{N})$ deposition, the paper summarizes the definition, form and amount of nutrient from the environment (NFE) and the relationship between NFE and anthropogenic reactive $\mathrm{N}$ emission. Based on our own study and published articles, we find that $\mathrm{N}$ wet and dry deposition has been an important nutrient resource in agricultural and natural ecosystems in China. The total amount of $\mathrm{N}$ deposition and other environment-derived $\mathrm{N}$ in China was up to $18 \mathrm{Tg} \mathrm{N} / \mathrm{a}$, equal to approximately $60 \%$ of the national $\mathrm{N}$ fertilizer consumption. Nitrogen deposition is expected to contribute substantially to nutrient cycling and net primary productivity in various ecosystems. Therefore, it is crucial to utilize this environment-derived nutrient resource by integrated nutrient resource management in order to realize the sustainable development of both agricultural and non-agricultural ecosystems.
\end{abstract}

Keywords: atmospheric deposition; nitrogen; nutrient management; ecological impacts

With the exacerbation of global environmental problem caused by anthropogenic reactive nitrogen $(\mathrm{N})$ emissions (Vitousek et al., 1997; Holland et al., 1999), nutrients from the environment (NFE) were paid more and more attention (Galloway et al., 2004; Liu et al., 2004; Liu and Zhang, 2009). However, what is the NFE and how about the relationship between NFE and anthropogenic activity? How to understand the effect of NFE on natural ecosystem, especially agroecosystem? A series of these problems need scientific explanation in order to provide scientific support for better utilization of the NFE and the avoidance of its negative effects. As an example of atmospheric $\mathrm{N}$ deposition, this paper discussed the definition, form, characteristic of temporal and spatial distribution of the NFE as well as the impacts of NFE on nutrient cycling and management in ecosystems.

\section{Introduction of NFE}

The NFE is a general designation of all kinds of nutrients in terrestrial and aquatic ecosystems, which comes from atmosphere, hydrosphere and lithosphere through physical, chemical, and biological processes. It includes nutrients from atmospheric deposition, irrigation water, biological $\mathrm{N}$ fixation, seeds and seedlings. The NFE, soil and fertilizer derived nutrients are three major nutrient resources for croplands (Zhang et al., 2003). From the aspect of components, NFE includes nitrogen $(\mathrm{N})$, phosphorus $(\mathrm{P})$, potassium $(\mathrm{K})$, and all other essential elements. However, in the view of quantity and ecological impact, $\mathrm{N}$ and sulfur (S) are the two most important components of NFE, both of which mainly come from atmospheric deposition (including dry and wet deposition). As $\mathrm{N}$ plays even more important role for plant nutrition and environmental pollution, we will give a detailed discussion on atmospheric $\mathrm{N}$ deposition in this paper.

Atmospheric $\mathrm{N}$ deposition refers to the process whereby airborne nitrogenous compounds (inorganic $\mathrm{N}$ including $\mathrm{NH}_{3}$, particulate $\mathrm{NH}_{4}{ }^{+}, \mathrm{NO}_{\mathrm{x}}, \mathrm{HNO}_{3}$, and particulate $\mathrm{NO}_{3}{ }^{-}$, and organic $\mathrm{N}$ including urea,

Received 2010-04-13, accepted 2010-04-22

doi: 10.3724/SP.J.1227.2010.00137

* Corresponding author: XueJun LIU (E-mail: liu310@cau.edu.cn). The first, second and third authors contributed equally to this work. 
amines, proteins, and nucleic acids) are deposited on the Earth's surface by wet deposition and/or dry deposition) (Cornell et al., 2003). Since the industrial revolution, especially the widely application of synthetical ammonia production, atmospheric $\mathrm{N}$ deposition has become an important component in the global $\mathrm{N}$ cycle with increasing anthropogenic atmospheric reactive $\mathrm{N}$ emissions (Vitousek et al., 1997; Holland et al., 1999). It was estimated that the global atmospheric $\mathrm{N}$ deposition caused by anthropogenic activities has increased from $31.6 \mathrm{Tg}$ N/a in 1860 to $103 \mathrm{Tg}$ N/a in the early 1990s, and is expected to be a further increase to $195 \mathrm{Tg}$ N/a in 2050 due to the accelerated human demand for food and energy (Galloway et al., 2004). Meanwhile, nitrogenous compounds emitted to atmosphere could form aerosols and particular matters through a serial of physical and chemical reactions, and will be transported hundreds and thousands tons $\mathrm{N}$ away via the atmospheric circumfluence, causing regional and global problems on air pollution and $\mathrm{N}$ deposition. Therefore, atmospheric $\mathrm{N}$ deposition has become a global concern because of the exacerbation of anthropogenic activities and their effects (Matson et al., 2002). As a nutrient and a driving factor of acidification, elevated $\mathrm{N}$ deposition will reduce the biodiversity and ecological functions of various ecosystems via acidification and eutrophication (Paerl et al., 1985; Stevens et al., 2004). To date, China, West Europe and North America are the three hotspots of global $\mathrm{N}$ deposition (Dentener et al., 2006).

\section{Quantification method of NFE}

The amount of total NFE can be collected and measured by different methods (Liu and Zhang, 2009). Here we mainly introduce the direct and indirect quantification approaches on $\mathrm{N}$ wet and dry deposition. Methods for measuring other NFEs can also be seen from Zhu (1997), Liu and Zhang (2009).

\subsection{Direct quantification}

\subsubsection{Nitrogen wet deposition}

Currently, rain gauges and wet-only collectors are the main methods. Samples collected by rain gauges belong to bulk deposition because they comprise part of dry deposition. However, samples collected by wet-only collectors are real wet deposition because they only collected rainfall or snow when precipitation or snow happens (Liu et al., 2006). Generally, there were no significant difference between bulk deposition and wet deposition. However, both of them have to be differentiated in arid area or regions dust storm occurs regularly.

To prevent losses and the $\mathrm{N}$ transformation between $\mathrm{N}$ components, samples have to be stored in refrigerators immediately after each collection. The dissolved inorganic $\mathrm{N}$ (DIN) $\left(\mathrm{NH}_{4}{ }^{+}-\mathrm{N}\right.$ and $\left.\mathrm{NO}_{3}{ }^{-}-\mathrm{N}\right)$ concentration in the wet deposition can be analyzed by continuous flow analyzer (CFA) or ion chromatogram (IC). The total dissolved N (TDN) in the wet deposition can be analyzed using the alkaline persulfate-oxidation (to nitrate) method followed by ultraviolet spectrophotometry. The dissolved organic $\mathrm{N}$ is the difference between TDN and DIN (Zheng et al., 2007).

\subsubsection{Nitrogen dry deposition}

Compared to wet deposition, atmospheric $\mathrm{N}$ dry deposition is more difficult to collect and measure. The main reason is that the occurrence of dry deposition is close related to the physical, chemical and biological traits of the surface of deposited collector, and some atmospheric reactive nitrogenous components $\left(\mathrm{NH}_{3}\right)$ can bidirectional flow, both of them could produce large uncertainty of atmospheric $\mathrm{N}$ dry deposition fluxes (Schjoerring et al., 2001).

Currently, there are two methods for the determination of $\mathrm{N}$ dry deposition. One is inferential method, with which the atmospheric reactive nitrogenous components are collected by passive or active samplers. Atmospheric concentration could be obtained after analyzing these samples and meteorological parameters. $\mathrm{N}$ dry deposition fluxes at unit time could be estimated by multiplying the measured concentration of reactive nitrogen with time and deposition velocities obtained from literatures (Schmitta et al., 2005; Shen et al., 2009). The other one is micrometeorological method, such as vertical gradient and eddy correlation, based on the principle of microclimatology. The $\mathrm{N}$ dry deposition fluxes could be calculated by detecting gradient variances of nitrogenous components rapidly and combining with micrometeorological conditions (Fowler et al., 2001). Compared between these two methods, the former one is relatively easier to realize because the concentration of 
atmospheric nitrogenous components could be obtained only when there are meteorological parameters and appropriate collectors for air and aerosol. And the deposition velocities of these reactive nitrogenous components are determinate in each ecosystem, the $\mathrm{N}$ dry deposition fluxes thereby could be calculated according to them. The later one is more difficult to carry out because expensive instruments and wide homogenous underlying surface (the ratio of measured height to radius is $1: 100$ ) are needed in this method. Even in developed European and American countries, there are few laboratories which could assume this method. Nowadays, the Environment and Nutrient Research Group in China Agricultural University (CAU) has adopted passive samplers, high volume particulate samplers and Denuder Long Lerm Atmospheric Sampling systems to measure the N dry deposition fluxes in North China Plain (NCP). The preliminary results showed that there is serious atmospheric reactive $\mathrm{Nr}$ pollution and high $\mathrm{N}$ deposition fluxes in NCP (Shen et al., 2009).

\subsubsection{Other environmental nutrients}

The nutrient input from irrigative water could also be determined like wet deposition. Analyze nutrient concentrations after collecting irrigation samples, and then multiply with annual irrigation, the product is the amount of nutrient from irrigation. The nutrient amount from seeds and seedlings could also be calculated by multiplying nutrient concentration with dry weight of seeds and seedlings used. The nutrient amount from biological $\mathrm{N}$ fixation could be estimated by the ratio of fixed $\mathrm{N}$ to total uptake $\mathrm{N}$ by leguminous plants. It also could be evaluated with the natural ${ }^{15} \mathrm{~N}$ abundance method or the $\mathrm{C}_{2} \mathrm{H}_{2}$ (ethyne) deoxidize method (Hardarson et al., 1993; Aveline et al., 1996).

\subsection{Indirect quantification}

\subsubsection{Estimation from zero-N soils}

This is an indirect method for quantification of NFE, based on the $\mathrm{N}$ uptake in plants aboveground from the zero-N plots. Such estimation includes soil N, resulting in an overestimation of the nutrient amount of NFE. However, it could be used as an indirect measurement of airborne $\mathrm{N}$ deposition in long-term experiments (LTEs) (more than ten years) because it has reached a dynamic equilibrium for the $\mathrm{C}$ and $\mathrm{N}$ con- tents in the soil of LTEs (Jenkinson et al., 2004). There are more than one hundred LTEs with history longer than ten years in China. We can get a general understanding about the amount and distribution of NFE by summarizing $\mathrm{N}$ uptake by crops from the zero-N plots of these LTEs.

\subsubsection{Biomonitoring}

It is a low cost measurement used in the monitoring of air and water pollution. There are two biomonitoring methods: (1) an Integral Total Nitrogen Input (ITNI) system based on ${ }^{15} \mathrm{~N}$ dilution technique (Russow et al., 2001), which is a sand-plant system; (2) plant indicator based on the passive response to airborne $\mathrm{N}$ deposition. And the familiar indicator plants include lichen, moss, herbage, and leaves of trees (Sutton et al., 2004).

The principle for the INTI system is ${ }^{15} \mathrm{~N}$ isotope dilution method which is fitted to crops with short lifecycle. At the start of the experiment the indicator plants was planted in sand and the sand-plant system was labeled with enriched ${ }^{15} \mathrm{~N}$ material. As the plants grew, the tracer was diluted by the input of atmospheric $\mathrm{N}$ (with natural ${ }^{15} \mathrm{~N}$ abundance). After harvest, ${ }^{15} \mathrm{~N}$ abundance in the various parts of the plants and in the sand and nutrient solution could be analyzed by mass spectrometry and the amount of $\mathrm{N}$ deposited from the atmosphere was calculated from the extent of ${ }^{15} \mathrm{~N}$ dilution (Russow et al., 2001; He et al., 2007).

Nitrogen in lichen and moss plant mainly originates from airborne $\mathrm{N}$ wet/dry deposition because both of them grow on rock surface. Therefore the $\mathrm{N}$ concentration undoubtedly could reflect the pollution degree of atmospheric reactive $\mathrm{N}$ and the deposition rates (Pitcairn et al., 2006). For the same reason, $\mathrm{N}$ concentration in the aboveground or foliar $\mathrm{N}$ in higher plants (especially for $\mathrm{NH}_{4}{ }^{+}-\mathrm{N}$ ) and even the ratio of $\mathrm{N}$ to $\mathrm{P}$ concentrations also have some relationship to the concentration of atmospheric reactive $\mathrm{N}$ species and their deposition rates. Therefore $\mathrm{N}$ in those lower and higher plants can indirectly indicate the amount of airborne $\mathrm{N}$ deposition. However, a mathematic relation (i.e. a linear regression equation) has to be established between such bio-monitoring results and atmospheric reactive $\mathrm{N}$ concentrations or the direct measurements of $\mathrm{N}$ deposition (Sutton et al., 2004; Pitcairn et al., 2006). 


\section{Amount and regional characteristic of NFE in China}

Atmospheric $\mathrm{N}$ deposition contributes soil and water acidification, but it is also an important environmental nutrient resource. Traditionally the airborne $\mathrm{N}$ input could be neglected because of the high application rates of $\mathrm{N}$ and organic fertilizers into the agro-ecosystems, which was disturbed intensively by anthropogenic activities. According to a report by the US national atmospheric deposition (NADP) network in recent two decades, annual $\mathrm{N}$ wet deposition was

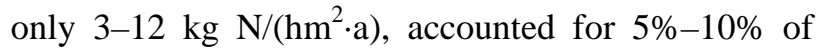
crop N requirement (NADP, 2007). Studies showed that $\mathrm{N}$ wet deposition ranged from $15-20 \mathrm{~kg} \mathrm{~N} /\left(\mathrm{hm}^{2} \cdot \mathrm{a}\right)$ in the 1980s (Zhu et al., 1997). But all of these results did not include the contribution of $\mathrm{N}$ dry deposition. Recently, some results showed that the amount and effect of $\mathrm{N}$ deposition on agro-ecosystems could be much higher than previous estimation (He et al., 2007, 2010). The results from the Broadbalk LTEs of Lausanne in UK showed that the amount of annual airborne $\mathrm{N}$ wet and dry deposition was up to $44 \mathrm{~kg}$ $\mathrm{N} /\left(\mathrm{hm}^{2} \cdot \mathrm{a}\right)$ according to wheat $\mathrm{N}$ uptake from the zero- $\mathrm{N}$ plots, while the $\mathrm{N}$ amount in rainfall was only $9 \mathrm{~kg} \mathrm{~N} / \mathrm{hm}^{2}$ during the same period (Goulding et al., 1998). Using the LTEs of Halle and the ITNI system, Weigel et al. (2000) reported 50-60 kg N/(hm².a) airborne $\mathrm{N}$ deposition into agro-ecosystems in Germany. The total $\mathrm{N}$ deposition values were largely greater than the amount of local $\mathrm{N}$ wet deposition. Our research found that the annual total N deposition in NCP was about $80-90 \mathrm{~kg} \mathrm{~N} / \mathrm{hm}^{2}$ (He et al., 2007) and 43-55 kg $\mathrm{N} / \mathrm{hm}^{2}$ deposited in wheat season (He et al., 2010), while the amount of annual $\mathrm{N}$ wet deposition was only one third of the total deposition (Liu et al., 2006; Zhang et al., 2008a). Therefore, it is not enough only take into account the amount of $\mathrm{N}$ wet deposition when atmospheric $\mathrm{N}$ deposition is considered, and dry deposition has also to be determined. Erisman et al. (1998) and Fowler et al. (2001) summarized the recent research progresses on atmospheric $\mathrm{N}$ dry deposition for both methodology and the understanding of deposition processes.

Nowadays, the research about atmospheric $\mathrm{N}$ dry deposition is still scarce in China. Therefore the amount and the characteristics of regional distribution of NFE in China were evaluated mainly based on our recent work and publications. To simplify the calculation, the total amount of $\mathrm{N}$ deposition, including wet and dry deposition, can be calculated through the estimation of wet deposition by assuming that the ratio of wet deposition to dry deposition is 1:1 according to some previous findings (Erisman et al., 1998). Annual precipitation in China was about $600 \mathrm{~mm}$ (China Agricultural Yearbook, 2001-2007), and the average $\mathrm{N}$ (the sum of $\mathrm{NH}_{4}{ }^{+}-\mathrm{N}, \mathrm{NO}_{3}{ }^{-}-\mathrm{N}$, and dissolved organic $\mathrm{N}$ ) concentration in rainfall across China was about 1.3 mg N/L. Based on this, the amount of $\mathrm{N}$ from wet deposition would amount to $7.50 \mathrm{Tg} \mathrm{N} / \mathrm{a}$, and that from wet and dry deposition would be $15 \mathrm{Tg}$ N/a in the Mainland in China (Table 1). Similarly, $\mathrm{N}$ wet and dry deposition in China was found to be $7.4 \mathrm{Tg}$ N/a and 11.2 Tg N/a in the 1980s and 1990s (Table 1). Such estimation is consistent with results of anthropogenic $\mathrm{NH}_{3}$ and $\mathrm{NO}_{\mathrm{x}}$ emission inventory in China since 1980 but slightly higher than total $\mathrm{N}$ deposition values during 1993 and 2003 reported by Lu and Tian (2007). It was roughly estimated that about one fourth of these $\mathrm{N}$ would deposit into agro-ecosystems according to the total amount of annual $\mathrm{N}$ deposition about $30 \mathrm{~kg} \mathrm{~N} /\left(\mathrm{hm}^{2} \cdot \mathrm{a}\right)$ in croplands, and the rest three fourths would deposit into forest, grassland, and aquatic ecosystems in China. If the $\mathrm{N}$ from biological $\mathrm{N}$ fixation (2.0 Tg N/a), irrigation (0.5 Tg N/a), seeds and seedlings ( $0.5 \mathrm{Tg} \mathrm{N} / \mathrm{a})$ was taken into account, the sum of NFE would be up to $18 \mathrm{Tg} \mathrm{N} /\left(\mathrm{hm}^{2} \cdot \mathrm{a}\right)$, accounting for $60 \%$ of the national annual $\mathrm{N}$ fertilizer consumption (China Agriculture Yearbook, 20012007). If only considered the amount of NFE input into croplands, it would amount to $7.0 \mathrm{Tg}$ N/a, approximating one fourth of nitrogenous fertilizer applications in the agroecosystems. In this sense, we should pay more attention to the contribution of NFE to plant nutrition in croplands.

Table 1 Anthropogenic emissions of $\mathrm{NH}_{3}$ and $\mathrm{NO}_{x}$ in China since the 1980 s

\begin{tabular}{ccccc}
\hline N emission & $1980 \mathrm{~s}$ & $\begin{array}{c}1990 \mathrm{~s} \\
(\text { Tg N/a) }\end{array}$ & Average \\
& \multicolumn{5}{c}{ 2000s } & \\
\hline $\mathrm{NH}_{3}-\mathrm{N}$ & 5.84 & 9.54 & 12.0 & 9.13 \\
$\mathrm{NO}_{\mathrm{x}}-\mathrm{N}$ & 1.41 & 2.69 & 4.31 & 2.63 \\
Total & 7.25 & 12.2 & 16.3 & 11.7 \\
\hline
\end{tabular}

Data source: Liu and Zhang (2009). 
On the other hand, there was a large regional difference about NFE in China. Generally, the amount of NFE in the inland areas was lower than that in mid-eastern and coastal areas of China, but it was higher than that in the Tibetan Plateau and northwest region of China. For example, our previous study has showed that the amount of inorganic $\mathrm{N}$ and organic $\mathrm{N}$ from wet deposition was about $27 \mathrm{~kg} \mathrm{~N} /\left(\mathrm{hm}^{2} \cdot \mathrm{a}\right)$ and 5 $\mathrm{kg} \mathrm{N} /\left(\mathrm{hm}^{2} \cdot \mathrm{a}\right.$ ) in NCP (Zhang et al., 2008a; Zhang et al., 2008b). The amount of wet deposition was positively related with precipitation, and that occurred from June to September nearly accounted for two third of that happened in the whole year because of the high precipitation during this period. There are three grades about wet deposition of inorganic $\mathrm{N}\left(\mathrm{NH}_{4}{ }^{+}-\mathrm{N}\right.$ and $\mathrm{NO}_{3}{ }^{-}-\mathrm{N}$ ) in China (Liu and Zhang, 2009): high deposition regions (>25 kg N/(hm².a)) like Shanghai, Beijing, Henan, Shandong, Sichuan, Chongqing, Jiangsu, Zhejiang, and Jiangxi, etc.; medium deposition regions (15 to $25 \mathrm{~kg} \mathrm{~N} /\left(\mathrm{hm}^{2} \cdot \mathrm{a}\right)$ ) like Hebei, Hunan, Hubei, Shannxi, Liaoning, Fujian, and Guangdong, etc.; low deposition regions (< $15 \mathrm{~kg} \mathrm{~N} /\left(\mathrm{hm}^{2} \cdot \mathrm{a}\right)$ ) like Yunnan, Guizhou, Xizang, Inner Mongolia, Xinjiang, Gansu, Jilin, Heilongjiang, and so on. If $\mathrm{N}$ deposition and the situation of local economy are linked together, we would find that the amount of atmospheric $\mathrm{N}$ deposition is higher in those developed areas than those less developed areas (Lu and Tian, 2007). This can be explained that higher emissions of both reduced and oxidized $\mathrm{N}$ species are greater in developed areas than undeveloped areas due to faster growth of economy in the developed areas. In addition, the small amount of rainfall in the arid and semi-arid area of western China is also an important reason for the low $\mathrm{N}$ wet deposition in those areas. However, the contribution of $\mathrm{N}$ dry deposition to total $\mathrm{N}$ deposition in these areas is significantly greater than that in south rainy regions. As a part of $\mathrm{N}$ dry deposition, the $\mathrm{N}$ from sand or dust storm occurred mainly during winter and spring season in northern and northwestern China is a considerable contributor to annual input of NFE. It was estimated that the amount of $\mathrm{N}$ input from the dust storm happened on 16-17 April 2005 in Beijing amounted to $6,000 \mathrm{t}$, corresponding to $4 \mathrm{~kg} \mathrm{~N} / \mathrm{hm}^{2}$ of $\mathrm{N}$ dry deposition in the whole Beijing area (Liu and Zhang, 2009).
Moreover, sand storm usually happens more than ten times each year in Xinjiang province, in this case, it is undoubtedly an important source of NFE in local agro-ecosystem and natural ecosystem (Wen et al., 2002).

\section{Impact of NFE on agro-ecosystems and natural ecosystems}

As a main component of NFE, atmospheric N deposition has a typical characteristic of nutrient resource and regional distribution. By this, counter measures of management according to the characteristic of each region have to be taken. In mid-eastern China, including the NCP and coastal developed areas, we have to pay more attention to the contribution of environmental $\mathrm{N}$ to croplands and water eutrophication, so as to make full use of this part of NFE and reduce unreasonable input of nitrogenous fertilizer for the efficient utilization of nutrient resources (Zhang et al., 2008). For instance, based on ${ }^{15} \mathrm{~N}$ dilution it was found that the total airborne $\mathrm{N}$ input into the whole maize-wheat rotation system was about $80-90 \mathrm{~kg} / \mathrm{hm}^{2}$, while only $50 \mathrm{~kg} / \mathrm{hm}^{2}$ could be available for maize and wheat plant in NCP (He et al., 2007), suggested that grain production would not be affected even if 50-80 kg $\mathrm{N} / \mathrm{hm}^{2} \mathrm{~N}$ fertilizer application was cut down. However, in the inland and west areas of China, as the contribution of atmospheric $\mathrm{N}$ deposition to agro-ecosystems is low, we have to focus on the potential effects of NFE (such as atmospheric N deposition) on forest and grassland ecosystems, including aboveground productivity, biodiversity, acidification, the potential of soil C storage and fixation, and the emission of greenhouse gases. It was found that the annual airborne $\mathrm{N}$ deposition would result in the loss of $17 \%$ species in grassland ecosystem although it was only $10 \mathrm{~kg} / \mathrm{hm}^{2}$ higher than the background value (Clark and Tilman, 2008). From this viewpoint, small increase in $\mathrm{N}$ deposition may have even greater impacts on plant biodiversity of natural ecosystems. Nevertheless, further studies should be conducted to verify this finding in other grassland and/or forest ecosystems.

With the development of industry and intensive agriculture, characterized by over-fertilization, high 
stocking rates of domestic animals, and rapid growth in energy consumption, there is a great increase about anthropogenic atmospheric reactive $\mathrm{N}$ emission. Total emissions of $\mathrm{NH}_{3}$ and $\mathrm{NO}_{\mathrm{x}}$ in China increased from $7.2 \mathrm{Tg} \mathrm{N} / \mathrm{a}$ in the $1980 \mathrm{~s}$ to $16.3 \mathrm{Tg} \mathrm{N} / \mathrm{a}$ in the 2000s (Table 1), consistent with the emission inventory by other studies (Streets et al., 2003; Anon, 2007). In this sense, it could be concluded that the atmospheric $\mathrm{N}$ deposition has already doubled since 1980 in China although the magnitude and its ecological impacts (e.g. the $\mathrm{N}$ deposition effects on productivity, soil potential of $\mathrm{C}$ storage, and biodiversity of natural and semi-ecosystems) are not very clear so far. But the patterns of $\mathrm{N}$ deposition and its potential effects should be identified through long-term $\mathrm{N}$ deposition monitoring networks and cross-site $\mathrm{N}$ addition experiments across China.

\section{Research recommendations}

China's current economy (GDP) is eight times of that in the 1980s and is expected to have further increase in the next decades (Liu and Diamond, 2008). As a result, China's anthropogenic $\mathrm{N}$ emissions mainly from agricultural production and fossil fuel combustion are likely to increase substantially in the near future. There are strong research needs to forecast reactive $\mathrm{N}$ emission trends in China considering all kinds of trade-offs in $\mathrm{N}$ emission increase or decrease due to expanded intensive agriculture (e.g. improved nutrient management and change of land use) and wider application of innovative techniques in traffic and industrial emission reduction.

It is difficult to evaluate the effect of pollution control measures on atmospheric reactive $\mathrm{N}$ (and other pollutants) concentrations and their deposition in

\section{References}

Aveline A. Soil N uptake and biological N fixation: a balanced system in grain legume crops. Grain Legumes, 1996, 14: 13-15.

China Agriculture Yearbook. Beijing: China Agriculture Yearbook Press, 2001-2007.

Clark C M, Tilman D. Loss of plant species after chronic low-level nitrogen deposition to prairie grasslands. Nature, 2008, 451: $712-715$.

Cornell S E, Jickells T D, Cape J N, et al. Organic nitrogen deposition on land and coastal environments: a review of methods and data. Atmospheric Environment, 2003, 37: 2173-2191.

Dentener F, Drevet J, Lamarque J F. Nitrogen and sulfur deposition on whole China without a national atmospheric deposition monitoring network. It is urgent to organize a long-term national deposition network (like the NADP) to monitor $\mathrm{N}$ wet and dry deposition across China. Cross-site $\mathrm{N}$ addition experiments along with typical forests, grasslands and aquatic ecosystems are greatly needed in China. Such long-term experiments could provide information on the impact of elevated $\mathrm{N}$ deposition on both terrestrial and marine ecosystems under the background of global change. Besides, Chinese scientists and governments should take actions for public education to improve their awareness of environmental protection in particular atmospheric $\mathrm{N}$ pollution and deposition.

In summary, $\mathrm{N}$ deposition as key component of NFE, has become an indicator of anthropogenic reactive $\mathrm{N}$ enrichment induced by expanding Chinese economy. Nitrogen deposition can not only cause rapid increase in environmental nutrient input in some intensive agricultural ecosystems (He et al., 2010) but also lead to detrimental effects on many natural and semi-natural ecosystems in those less anthropogenic impacted regions (Stevens et al., 2004; Phoenix et al., 2006; Clark and Tilman, 2008). We believe that heavy $\mathrm{N}$ deposition could be used as an important nutrient resource in croplands. On the other hand, the potential risk of $\mathrm{N}$ deposition on grasslands, forests and aquatic ecosystems should be controlled within the acceptable level (below critical load) by substantially reducing the reactive $\mathrm{N}$ emissions to the environments.

\section{Acknowledgements}

This study was funded by the One-hundred Talents Program of CAS, the Special Fund for Agricultural Profession (200803030) and the Sino-German project (DFG Training Group, GK1070).

regional and global scales: a multimodel evaluation. Global Biogeochemical Cycles, 2006, 20, GB4003, doi: 10.1029/2005GB002672.

Erisman J W, Bleeker A, van Jaarsveld J A. Evaluation of ammonia emission abatement on the basis of measurements and model calculations. Environmental Pollution, 1998, 102 (Suppl.1): 269-274.

Fowler D, Coyle M, Flechard C, et al. Advances in micrometeorological methods for the measurement and interpretation of gas and particle nitrogen fluxes. Plant and Soil, 2001, 228: 117-129.

Galloway J N, Dentener F J, Capone D G, et al. Nitrogen cycles: past, present, and future. Biogeochemistry, 2004, 70: 153-226.

Goulding K W T, Bailey N J, Bradbury N J, et al. Nitrogen deposition 
and its contribution to nitrogen cycling and associated soil processes. New Phytologist, 1998, 139: 49-58.

Hardarson G, Danso S K A. Methods for measuring biological nitrogen fixation in grain legumes. Plant and Soil, 1993, 152: 19-23.

Holland E A, Dentener F J, Braswell B H, et al. Contemporary and pre-industrial global reactive nitrogen budgets. Biogeochemistry, 1999, 46: 7-43.

He C E, Liu X J, Fangmeier A, et al. Quantifying the total airborne nitrogen-input into agroecosystems in the North China Plain. Agriculture, Ecosystems \& Environment, 2007, 121: 395-400.

He C E, Liu X J, Christie P, et al. Estimating total nitrogen deposition in agroecosystems in northern China during the wheat cropping season. Journal of Arid Land, 2010, 2(1): 2-8.

Holland E A, Dentener F J, Braswell B H, et al. Contemporary and pre-industrial global reactive nitrogen budgets. Biogeochemistry, 1999, 46: 7-43.

Jenkinson D S, Poulton P R, Johnston A E, et al. Turnover of nitrogen-15-labeled fertilizer in old grassland. Soil Science Society of American Journal, 2004, 68: 865-875.

Lee J A, Caporn S J M. Ecological effects of atmospheric reactive nitrogen deposition on semi-natural terrestrial ecosystems. New Phytologist, 1998, 139: 127-134.

Liu J G, Diamond J. Revolution of China's environmental protection. Science, 2008, 319: 37-38.

Liu X J. Atmospheric nitrogen deposition and its impact on nutrient input to agroecosystems in China. Xinan Nongye Xuebao, 2004, 17(suppl.): 185-186.

Liu X J, Ju X T, Zhang Y, et al. Nitrogen deposition in agroecosystems in the Beijing area. Agriculture, Ecosystems \& Environment, 2006, 113: 370-377.

Liu X J, Zhang F S. Nutrient from environment and its effect in nutrient resources management of ecosystems. Arid Zone Research, 2009, 26: 306-311.

Lu C Q, Tian H Q. Spatial and temporal patterns of nitrogen deposition in China: synthesis of observational data. Journal of Geophysical Research 2007, 112, D22S05, doi: 10.1029/2006JD007990.

Matson P, Lohse K A, Hall S J. The globalization of nitrogen deposition: consenquences for terrestrial ecosystems. Ambio, 2002, 31: 113-119.

NADP. Nitrogen in the nation's rain. http://nadp.swa.uiuc.edu [2007-11-05].

Paerl H W. Enhancement of marine primary production by nitrogen-enriched acid rain. Nature, 1985, 315: 747-749.

Phoenix G K, Hicks W K, Cinderby S, et al. Atmospheric nitrogen deposition in world biodiversity hotspots: the need for a greater global perspective in assessing $\mathrm{N}$ deposition impacts. Global Change Biology, 2006, 12: 470-476.

Pitcairn C, Fowler D, Leith I, et al. Diagnostic indicators of elevated nitrogen deposition. Environmental Pollution, 2006, 144: 941-950.

Russow R, Bohme F, Neue H U. A new approach to determine the total airborne $\mathrm{N}$ input into the soil-plant system using ${ }^{15} \mathrm{~N}$ isotope dilution (ITNI): results for agricultural areas in central Germany. The Scien- tific World, 2001, 1(Supp1.2): 255-260.

Schjoerring J K, Mattsson M. Quantification of ammonia exchange between agricultural cropland and the atmosphere: measurements over two complete growth cycles of oilseed rape, wheat, barley and pea. Plant and Soil, 2001, 228: 105-115.

Stevens C J, Dise N B, Mountford O, et al. Impact of nitrogen deposition on the species richness of grasslands. Science, 2004, 303: 1876-1879.

Streets D G, Bond, T C, Carmichael G R, et al. An inventory of gaseous and primary aerosol emissions in Asia in the year 2000, Journal of Geophysical Research. 2003, 108(D21), 8809, doi: 10.1029/ 2002JD003093.

Sutton M A, Pitcairn C E R, Whitfield C P. Bioindicator and biomonitoring methods for assessing the effects of atmospheric nitrogen on statutory nature conservation sites. JNCC Report. 2004.

Schmitta M, Thönib L, Waldnera P, et al. Total deposition of nitrogen on Swiss long-term forest ecosystem research (LWF) plots: comparison of the throughfall and the inferential method. Atmospheric Environment, 2005, 39: 1079-1091.

Shen J L, Tang A H, Liu X J, et al. High concentrations and dry deposition of reactive nitrogen species at two sites in the North China Plain. Environmental Pollution, 2009, 157: 3106-3113.

Vitousek P M, Aber J D, Howarth R W, et al. Human alteration of the global nitrogen cycle: sources and consequences. Ecological Applications, 1997, 7: 737-750.

Weigel A, Russow R, Korschens M. Quantification of airborne N-input in long-term field experiments and its validation through measurements using ${ }^{15} \mathrm{~N}$ isotope dilution. Journal of Plant Nutrition \& Soil Science, 2000, 163: 261-265.

Wen Q, Guan X, Cui W G. Study on dustfall and its effect on soils in Hotan, Xinjiang. Arid Zone Research, 2002, 19(3): 1-5.

Zhang F S. Integrated Nutrient Resource Management. Beijing: China Agricultural University Press, 2003. 4-13.

Zhu Z L, Wen Q X, Freney J R. Nitrogen of Soils in China. Dordrecht, Boston, London: Academic Publishers, 1997. 323-338.

Zhang F S. Research and Application of Integrated Nutrient Resource Management Technology Aiming at High Crop Yield and Environmental Protection. Beijing: China Agricultural University Press, 2008. 1-9.

Zhang Y, Liu X J, Fangmeier A, et al. Nitrogen inputs and isotopes in precipitation in the North China Plain. Atmospheric Environment, 2008a, 42: 1436-1448.

Zhang Y, Zheng L, Liu X J, et al. Evidence for organic N deposition and its anthropogenic sources in China. Atmospheric Environment, 2008b, 42: 1035-1041.

Zheng L X, Liu X J, Zhang F S. Progress on atmospheric organic nitrogen deposition. Acta Ecologia Sinica, 2007, 27: 3828-3834.

Zhu Z L. Nitrogen balance and cycling in agroecosystems of China. In: Zhu Z L, Wen Q X, Freney J R. Nitrogen in Soils of China. Dordrecht, Boston, London: Academic Publishers, 1997. 323-338. 